\title{
Habitual Physical Activity and Diabetes Control in Young and Older Adults with Type II Diabetes: A Longitudinal Correlational Study
}

\author{
Chia-Hsun Chang ${ }^{1,+}$, Ching-Pyng Kuo ${ }^{2,3,+} \mathbb{D}$, Chien-Ning Huang ${ }^{4,5}$, Shiow-Li Hwang ${ }^{6}$, Wen-Chun Liao ${ }^{7,8, *}$ \\ and Meng-Chih Lee $4,9,10,11, * \mathbb{D}$
}

Citation: Chang, C.-H.; Kuo, C.-P.; Huang, C.-N.; Hwang, S.-L.; Liao, W.-C.; Lee, M.-C. Habitual Physical Activity and Diabetes Control in Young and Older Adults with Type II Diabetes: A Longitudinal Correlational Study. Int. J. Environ. Res. Public Health 2021, 18, 1330. https:// doi.org/10.3390/ijerph18031330

Academic Editor: Li Ming Wen

Received: 4 January 2021

Accepted: 27 January 2021

Published: 2 February 202

Publisher's Note: MDPI stays neutral with regard to jurisdictional claims in published maps and institutional affiliations.

Copyright: (C) 2021 by the authors. Licensee MDPI, Basel, Switzerland. This article is an open access article distributed under the terms and conditions of the Creative Commons Attribution (CC BY) license (https:/ / creativecommons.org/licenses/by/ $4.0 /)$.
1 Department of Nursing, Taichung Veterans General Hospital, Taichung 40705, Taiwan; up2u5400@vghtc.gov.tw

2 School of Nursing, Chung Shan Medical University, Taichung 40201, Taiwan; pyng@csmu.edu.tw Department of Nursing, Chung Shan Medical University Hospital, Taichung 40201, Taiwan Institute of Medicine, Chung Shan Medical University, Taichung 40201, Taiwan; cshy049@csh.org.tw Department of Internal Medicine, Chung Shan Medical University Hospital, Taichung 40201, Taiwan School of Nursing, Asia University, Taichung 41354, Taiwan; slhwang@asia.edu.tw

School of Nursing, China Medical University, Taichung 406040, Taiwan

Department of Nursing, China Medical University Hospital, Taichung 40447, Taiwan

Department of Family Medicine, Taichung Hospital, Ministry of Health and Welfare, Taichung 40343, Taiwan

Institute of Population Health Sciences, National Health Research Institutes, Miaoli 35053, Taiwan

11 College of Management, Chaoyang University of Technology, Taichung 413310, Taiwan

* Correspondence: wcl@mail.cmu.edu.tw (W.-C.L.); mcl@taic.mohw.gov.tw (M.-C.L.)

+ Equal contributor as the first author.

\begin{abstract}
This study aimed to determine whether daily physical activity in young and older adults with T2DM is associated with diabetes control. A prospective correlational study involving 206 young ( $\leq 65$ years) and older (>65 years) adults was conducted. The International Physical Activity Questionnaire was used to assess their daily physical activity levels. Patients' mean HbA1c level was $7.8 \%( \pm 1.4)$, and $95.9 \%$ of patients had unsatisfactory diabetes control. Performing more minutes per week of moderate-intensity daily physical activity was associated with a lower risk of glycemia in both young and older adults. Furthermore, moderate daily physical activity significantly lowered the risk of glycemia. Health personnel must encourage patients to engage in moderate daily physical activities to improve diabetes control.
\end{abstract}

Keywords: daily physical activity; diabetes control; International Physical Activity Questionnaire (IPAQ); Type II Diabetes Mellitus (T2DM)

\section{Introduction}

The prevalence of Type II Diabetes Mellitus (T2DM) is increasing worldwide and in Taiwan [1]. The increasing prevalence and incidence of T2DM inflict a considerable burden on healthcare systems due to long-term complications [1]. Age has an impact on mortality and vascular complications with T2DM, and young age at diabetes is associated with a 3 5\% increased risk of mortality and complications [2]. Managing T2DM is crucial for preventing or controlling diabetes-related complications and even more important for younger diabetes [2]. The American Diabetes Association 2018 [3] suggested that T2DM should be controlled by maintaining the "ABC" standard, which refers to a patient's hemoglobin A1c (HbA1c) levels, blood pressure, and low-density lipoprotein cholesterol (LDL-C) levels. Exercise can improve glucoregulatory activity, stimulate endothelial cells to release vasodilators (e.g., nitric oxide and bradykinin), increase baroreflex sensitivity, control blood pressure [4], facilitate the reverse transport of cholesterol, and accelerate mature rates of high-density lipoprotein [5]. Numerous studies have shown that exercise undertaken by patients with T2DM facilitates disease control [6-10]. The results of a 
meta-analysis of progressive resistance exercise showed that patients with T2DM who engaged in exercise three times a week for more than 8 weeks reduced their $\mathrm{HbA} 1 \mathrm{c}$ levels by $0.3 \%$ [6]. Umpierre et al. (2011) further synthesized related literature and found that engaging in structured supervised exercise, including aerobic, resistance, or combined training exercises, three times a week for $150 \mathrm{~min}$ a week for 12 weeks or longer, reduced patients' $\mathrm{HbA} 1 \mathrm{c}$ levels by $0.67 \%$ [7]; however, undertaking exercise advice partially or participating in exercise that was not supervised, reduced HbA1c levels by $0.43 \%$ [7]. These results suggest the effectiveness of exercise, with varied intensity, patterns, and methods, for diabetes control.

Physical activity is defined as bodily movement produced by skeletal muscles with energy expenditure [11]. A simple category for the total energy expenditure produced by physical activity can be identified as at work and leisure, except for a small amount of energy production during sleep [11]. Thus, physical activity includes occupational and leisure-time activities, such as sports, conditioning, household chores, or other activities [11]. Exercise is a subcategory of physical activity and a part of physical activities, with total daily physical activities consisting of exercise and non-exercise activities. Performing physical activities, including non-exercise activities, may also affect the control of diabetes.

Physical activity is further divided into low-, moderate-, or heavy-intensity activities, which are mutually exclusive [11]. A study compared continuous low- to moderateintensity endurance-type exercise (50\% peak oxygen uptake, $\mathrm{VO}_{2}$ peak) and moderateto high-intensity endurance-type exercise $\left(75 \% \mathrm{VO}_{2}\right.$ peak) to investigate the intensity of physical activity required for diabetes control and found similar effects of both types on reducing $\mathrm{HbA} 1 \mathrm{c}$ levels or LDL-C levels in obese T2DM patients when their medication and diet were well-controlled [8]. Another study compared different intensities of physical activity patterns and found similar effects of engaging in moderate exercise $(60 \%$ maximal oxygen uptake, $\mathrm{VO}_{2} \mathrm{max}$ ) for $30 \mathrm{~min}$ every day or $60 \mathrm{~min}$ every other day on glycemic levels in patients with T2DM [9]. These findings suggest the positive effect of varied intensity and frequency in performing physical activities on glycemic control in diabetes. Moderate-intensity physical activity performed either daily or every other day is effective for glycemic control. However, even if the amount of these effective physical activities were counted by levels of intensity, these studies all focused on structured exercise, and the non-exercise part of physical activities was not counted. A total of $53.8 \%$ of Asians participated in low-intensity exercise, $35 \%$ in moderate physical activity, and $11.2 \%$ in high physical activity [12]. If non-exercise physical activity can be included, patients might be able to more readily achieve a sufficient amount of physical activity to control diabetes.

A study compared the status of physical activities in patients whose diabetes was under control $(\mathrm{HbA} 1 \mathrm{c} \leq 7 \%, n=93)$ with those whose diabetes was not under control $(\mathrm{HbA} 1 \mathrm{c}>7 \%, n=117)$ and found that patients under control walked more minutes per week than did patients not under control (215.9 vs. $150.7 \mathrm{~min} /$ week, $\mathrm{t}=2.49, p<0.05)$ [10]. A low-intensity activity, such as walking 37 min per day for 6 days a week, was able to effectively control patients' glycemic levels [10]. People perform both exercise and nonexercise physical activities, and if non-exercise physical activities such as household or work tasks are counted in addition to exercise, a positive effect of total physical activity on glycemic control may be seen for patients with diabetes.

Whether or not daily physical activities, including work, walking, housework, gardening, leisure activities, and transportation, have a similar effect on diabetes control is not well-studied. Mynarski et al. (2012) investigated the effect of habitual physical activities on unemployed or retired patients with T2DM by using an accelerometer and the International Physical Activity Questionnaire (IPAQ) and found that daily habitual physical activity did not influence $\mathrm{HbA1c}$ levels [13]; however, this study had a small sample size $(n=31)$, and a larger population is needed for similar future studies. Moreover, engaging in structured exercises may require supervision. Time for exercise is even limited in younger adults when their time is occupied with work. Comparatively, daily physical activities such as work, walking, housework, or leisure activities can be undertaken in everyday life and 
are therefore simple, convenient, and easy to practice. Since the IPAQ is correlated with accelerometer measurements and can be an easy tool for physical activity assessment [13] in a larger sample size, this study used the IPAQ to assess patients' daily physical activity levels and explored whether levels of habitual physical activity undertaken by Taiwanese patients with T2DM were compatible with low-to-moderate-intensity exercise to generate benefits. Moreover, the age group divided by 65 years was stratified in this study to investigate if age plays roles on physical activity and glycemic control in type 2 diabetics.

\section{Methods}

\subsection{Research Design}

A cross-sectional survey with a 1-year medical follow-up was adopted in this study. Data were collected through structured interviews and medical record reviews at the endocrinology outpatient clinic of a medical center in Central Taiwan. Physicians in endocrine clinics asked for permission from diabetes patients and referred them to this study. Self-reported habitual physical activity was investigated through face-to-face interviews. Diabetes control, including HbA1c, blood pressure, and LDL-C levels, were followed-up every 3 months for 1 year after recruitment.

\subsection{Participants}

Diabetes patients aged 30 to 85 years, diagnosed with T2DM, who had no history of mental disorders (e.g., schizophrenia) or cognitive impairment (Mini-Mental State Examination, MMSE > 25 in those with a middle to high educational level, or 19 in those with a low education level or who were illiterate), could speak Mandarin Chinese or Taiwanese (or their family members could speak one of the languages), and lived in the community, were recruited.

Patients who were diagnosed with type I diabetes, gestational diabetes, exocrine pancreatic disease, drug-induced diabetes, or severe cardiovascular disease were excluded from this study. In addition, those who had severe depression or anxiety (Hospital Anxiety and Depression Scale, HADS > 5), cognitive impairment (MMSE $\leq 19$ ), a history of alcohol or drug abuse, or who were hospitalized during follow-up, were excluded. Two-hundredand-seventy-six patients were approached, of which 5 refused to participate and 65 were excluded from the analysis because of incomplete laboratory data. Two-hundred-and-six patients completed the study. Figure 1 shows the study recruitment procedure. This study was approved by the Institutional Review Board of Chun Shan Medical University Hospital (CSMUH CS09025). All the participants gave their informed consent to participate in this study.

\subsection{Measurements}

Demographic information. Personal data, including age, sex, occupation, work conditions, education level, marital status, living conditions, and number of years diagnosed with diabetes, were collected through face-to-face interviews. Patient privacy was respected during the interview.

Assessment of habitual physical activity. A short version of the IPAQ Taiwan version [14] was used in this study to assess patients' physical activity levels. The validity of the Content Validity Index of the IPAQ Taiwan version was greater than 0.8 , and the consistency between the English and Taiwan versions was greater than 0.9 , with a reliability of the intraclass correlation coefficient of 0.7-0.9 [14]. This questionnaire was employed to determine the average amount of time that the participants spent walking and performing high- and moderate-intensity activities during a 7-day period and the average amount of time spent sitting during a workday [14]. Only physical activity that continued for a minimum of $10 \mathrm{~min}$ was counted. Physical activity levels were estimated using a metabolic equivalent task (MET): (1) vigorous- or high-intensity activity refers to an activity of greater than 6 METs, such as running and climbing; (2) moderate-intensity activity refers to an activity of 3 to 6 METs, such as swimming and dancing; and (3) low-intensity activity refers 
to an activity of $<3$ METs, such as walking. The formula for calculating the amount of total physical activity per week (MET-min/wk) is as follows: $3 \times$ walking $(\mathrm{min}) \times$ number of days $+4.5 \times$ moderate-intensity activity $(\mathrm{min}) \times$ number of days $+6 \times$ high-intensity activity $(\mathrm{min}) \times$ number of days [14]. Three types of lifestyles were derived based on the total MET per week: (1) a high-intensity lifestyle denoted a person who undertook highintensity activities for a minimum of 3 days per week, achieving a total physical activity level of $1500 \mathrm{MET}-\mathrm{min} / \mathrm{wk}$ or a patient whose total physical activity (including walking and moderate- or high-intensity activities) for 7 days per week reached 3000 MET-min/wk; (2) a moderate-intensity lifestyle was defined as a person who engaged in high-intensity activities $20 \mathrm{~min}$ per day for a minimum of 3 days per week, undertook moderate-intensity activities for $30 \mathrm{~min}$ per day for a minimum of 5 days per week, walked $30 \mathrm{~min}$ per day for 7 days per week or who walked and engaged in moderate- or high-intensity activities for $>5$ days per week, with a total physical activity level reaching 600 MET-min/wk; and (3) a low-intensity lifestyle denoted a person whose physical activity level did not meet any of the aforementioned criteria (International Physical Activity Questionnaire, n. d.).

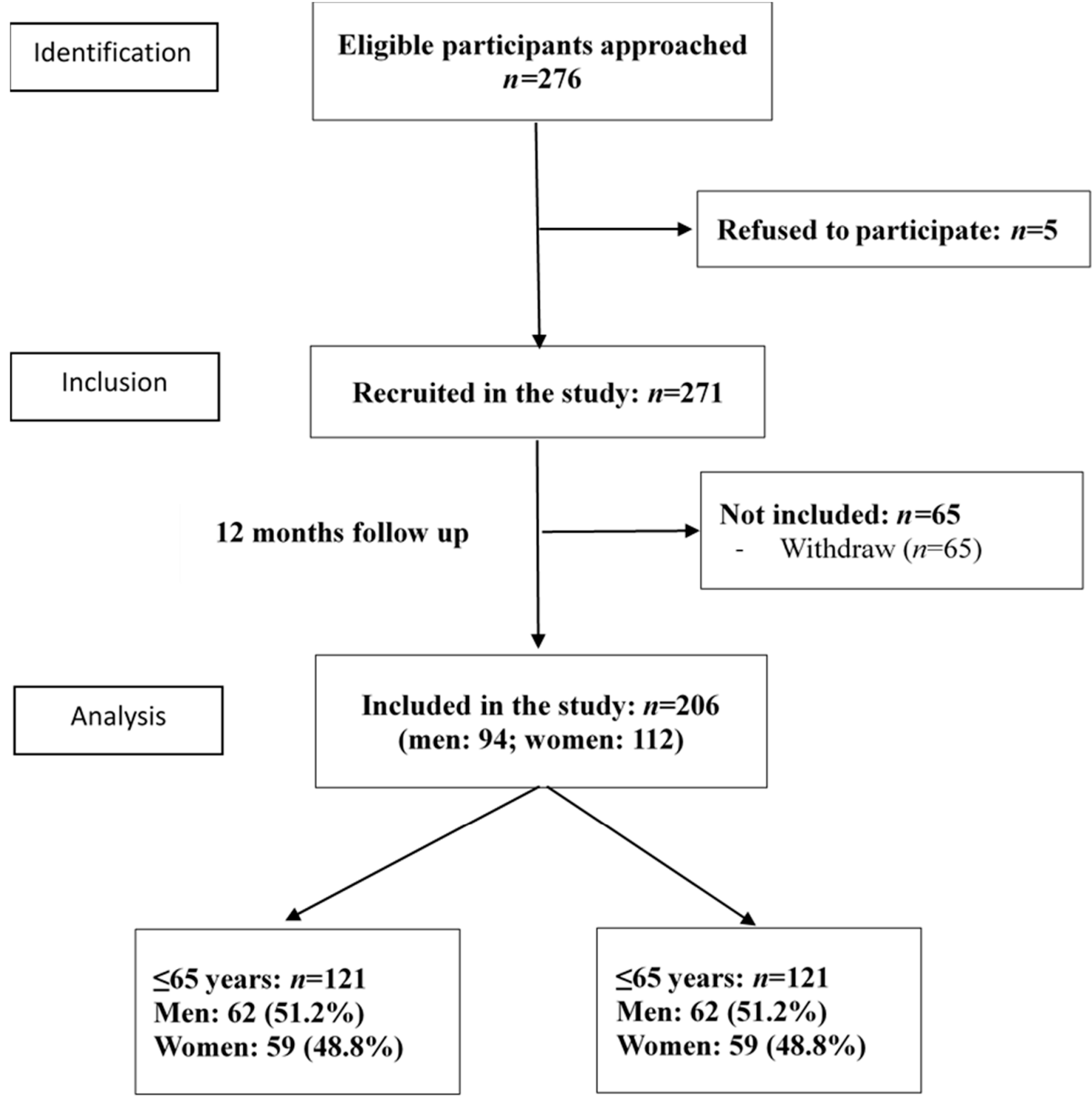

Figure 1. Recruiting flow chart. A total of 216 patients were recruited from an endocrinology outpatient clinic of a medical center. Eleven patients with missing data were excluded from this study. A total of 206 patients completed the baseline and 12 -month follow-up measures. Among them, 121 younger patients (age $\leq 65$ years) and 85 older patients (age $>65$ years) were analyzed separately in this study. 
Diabetes control. According to the ADA and guidelines in Taiwan [15], diabetes control is defined as $\mathrm{HbA1c} \leq 7 \%$, blood pressure $<140 / 90 \mathrm{mmHg}$ in older ( $>65$ years) adults and as $<130 / 80 \mathrm{mmHg}$ in younger adults, and LDL-C $<100 \mathrm{mg} / \mathrm{dL}$. After recruitment, the laboratory data of diabetes control in each participant was followed every 3 months for 1 year. These data were obtained from medical records, prospectively, after study enrollment.

\subsection{Data Analysis}

Descriptive statistics, including frequency, percentage, mean, and standard deviation, were used to understand sample distributions of physical activity level and control of diabetes. The Pearson correlation test was used to examine the univariate correlation between habitual physical activity and control of diabetes. Multiple logistic regression was used to examine the association between habitual physical activity and control of diabetes by using significant factors from the Pearson correlation test. Age, sex, and number of years diagnosed were set as confounding factors in the regression model. The significance level was set at $p<0.05$ and was two-tailed. The Statistical Package for Social Sciences (SPSS) for Windows, Version 26 software (SPSS Inc., Chicago, IL, USA) was used to analyze the data.

\section{Results}

\subsection{Demographic Characteristics}

A total of 271 patients participated in this study, 65 of whom withdrew with a completion rate of $76 \%$. Table 1 shows the demographic characteristics and diabetes control status of the participants. In this study, the average age of the participants was 62.5 years ( \pm 10.4 years); more than half of the patients were women, and the average duration of diabetes since diagnosis was 13.2 years ( \pm 7.8 years). Since the patients were distributed across a wide age range (33 82 years) and their physical health, activity levels, and comorbidities might have varied with age, the patients were divided into younger ( $\leq 65$ years) and older ( $>65$ years) groups. In the younger group, more patients were working, had a higher education, and were more obese than those in the older group (Table 1).

Table 1. Demographic Characteristics and Status of Diabetes Control in Younger ( $\leq 65$ Years) and Older ( $>65$ Years) Patients with T2DM.

\begin{tabular}{|c|c|c|c|c|c|c|c|c|}
\hline \multirow{2}{*}{ Variable } & \multicolumn{2}{|c|}{ All Patients } & \multicolumn{2}{|c|}{$\leq 65$ Years } & \multicolumn{2}{|c|}{$>65$ Years } & \multirow[b]{2}{*}{$X^{2}$} & \multirow[b]{2}{*}{$p$} \\
\hline & $n$ & $\%$ & $n$ & $\%$ & $n$ & $\%$ & & \\
\hline Gender & 206 & 100 & 121 & 58.7 & 85 & 41.3 & 3.718 & 0.054 \\
\hline Men & 94 & 45.6 & 62 & 51.2 & 32 & 37.6 & & \\
\hline Women & 112 & 54.4 & 59 & 48.8 & 53 & 62.4 & & \\
\hline Occupation & & & & & & & 34.191 & 0.000 \\
\hline Unemployed/retired & 138 & 67 & 63 & 52.1 & 75 & 88.3 & & \\
\hline Working & 68 & 33 & 58 & 47.9 & 10 & 11.8 & & \\
\hline Education level & & & & & & & 20.265 & 0.000 \\
\hline Illiterate & 25 & 12.1 & 5 & 4.1 & 20 & 23.5 & & \\
\hline$<12$ years & 147 & 71.4 & 90 & 74.4 & 57 & 67.1 & & \\
\hline$>12$ years & 34 & 16.5 & 26 & 21.5 & 8 & 9.4 & & \\
\hline Marital status & & & & & & & 2.910 & 0.088 \\
\hline Married & 160 & 77.7 & 99 & 81.8 & 61 & 71.8 & & \\
\hline Single/Divorced/separated/Widowed & 46 & 22.3 & 22 & 18.2 & 24 & 28.2 & & \\
\hline Number of years diagnosed & & & & & & & 26.732 & 0.000 \\
\hline 1 to 5 years & 27 & 13.1 & 23 & 19 & 4 & 4.7 & & \\
\hline 6 to 10 years & 58 & 28.2 & 40 & 33.1 & 18 & 21.2 & & \\
\hline 11 to 15 years & 55 & 26.7 & 32 & 26.4 & 23 & 27.1 & & \\
\hline 16 to 20 years & 35 & 17 & 19 & 15.7 & 16 & 18.8 & & \\
\hline$>20$ years & 28 & 13.6 & 6 & 5 & 22 & 25.9 & & \\
\hline Primary caregiver & & & & & & & 7.896 & 0.005 \\
\hline
\end{tabular}


Table 1. Cont

\begin{tabular}{|c|c|c|c|c|c|c|c|c|}
\hline \multirow{2}{*}{ Variable } & \multicolumn{2}{|c|}{ All Patients } & \multicolumn{2}{|c|}{$\leq 65$ Years } & \multicolumn{2}{|c|}{$>65$ Years } & \multirow[b]{2}{*}{$X^{2}$} & \multirow[b]{2}{*}{$p$} \\
\hline & $n$ & $\%$ & $n$ & $\%$ & $n$ & $\%$ & & \\
\hline Husband or wife & 126 & 61.2 & 84 & 69.4 & 42 & 49.4 & & \\
\hline Others & 79 & 38.5 & 37 & 30.6 & 42 & 50.0 & & \\
\hline \multicolumn{9}{|l|}{ Living condition } \\
\hline Living with spouse or children & 187 & 91 & 110 & 90.9 & 77 & 90.6 & 2.954 & 0.228 \\
\hline Solitary & 13 & 6.3 & 6 & 5 & 7 & 8.2 & & \\
\hline Others & 3 & 1.5 & 3 & 2.5 & 0 & 0 & & \\
\hline $\mathrm{BMI}, \mathrm{kg} / \mathrm{m}^{2}$ & & & & & & & 14.26 & 0.003 \\
\hline Underweight $(<18.5)$ & 4 & 1.9 & 3 & 2.5 & 1 & 1.2 & & \\
\hline Normal(18.5 24) & 69 & 33.5 & 31 & 25.6 & 38 & 44.7 & & \\
\hline Overweight(24-27) & 61 & 29.6 & 33 & 27.3 & 28 & 32.9 & & \\
\hline Obese(>27) & 72 & 35 & 54 & 44.6 & 18 & 21.2 & & \\
\hline \multicolumn{9}{|l|}{ Medications } \\
\hline Metformin or other oral drugs & 163 & $79.1 \%$ & 98 & $81.0 \%$ & 65 & $76.5 \%$ & 1.046 & 0.790 \\
\hline Insulin injection & 30 & $14.6 \%$ & 17 & $14.0 \%$ & 13 & $15.3 \%$ & & \\
\hline Combine insulin and other oral drugs & 11 & $5.3 \%$ & 5 & $4.1 \%$ & 6 & $7.1 \%$ & & \\
\hline Glycemic control & & & & & & & 0.556 & 0.456 \\
\hline $\mathrm{HbA} 1 \mathrm{c} \leq 7 \%$ & 62 & 30.1 & 34 & 28.1 & 28 & 32.9 & & \\
\hline $\mathrm{HbA} 1 \mathrm{c}>7 \%$ & 144 & 69.9 & 87 & 71.9 & 57 & 67.1 & & \\
\hline Blood pressure control ${ }^{1}$ & & & & & & & 13.75 & 0.000 \\
\hline Normal & 76 & 36.9 & 32 & 26.4 & 44 & 51.8 & & \\
\hline Abnormal & 130 & 63.1 & 89 & 73.6 & 41 & 48.2 & & \\
\hline LDL-C control & & & & & & & 6.541 & 0.011 \\
\hline$\leq 100 \mathrm{mg} / \mathrm{dl}$ & 87 & 42.2 & 42 & 34.7 & 45 & 52.9 & & \\
\hline$>100 \mathrm{mg} / \mathrm{dl}$ & 110 & 53.4 & 73 & 60.3 & 37 & 43.5 & & \\
\hline Diabetes control 2 & & & & & & & 3.823 & 0.051 \\
\hline Normal & 8 & 3.9 & 2 & 1.7 & 6 & 7.1 & & \\
\hline Abnormal & 189 & 91.7 & 113 & 93.4 & 76 & 89.4 & & \\
\hline \multicolumn{9}{|l|}{ Complications $^{3}$} \\
\hline Neuropathy & 34 & 16.5 & 21 & 17.4 & 13 & 15.3 & 0.154 & 0.695 \\
\hline Cardiovascular & 36 & 17.5 & 14 & 11.6 & 22 & 25.9 & 7.091 & 0.008 \\
\hline Nephropathy & 13 & 6.3 & 11 & 9.1 & 2 & 2.4 & 3.834 & 0.050 \\
\hline Eye problems & 59 & 28.6 & 14 & 11.6 & 45 & 52.9 & 41.811 & 0.000 \\
\hline
\end{tabular}

Note: ${ }^{1}$. Normal blood-pressure control: systolic blood pressure $<130 \mathrm{mmHg}$ and diastolic blood pressure $<80 \mathrm{mmHg}$ for aged $\leq 65$ years; systolic blood pressure $<140 \mathrm{mmHg}$ and diastolic blood pressure $<90 \mathrm{mmHg}$ for aged $>65$ years. ${ }^{2}$. Overall diabetes control: Normal $=$ all of the $\mathrm{HbA1c}$, blood pressure, and LDL-C are within normal range; abnormal: one of the HbA1c, blood pressure, and LDL-C are out of normal range. ${ }^{3}$. Neuropathy includes trembling feet and diabetes foot. Vascular disease includes hypertension, coronary artery syndrome and stroke. Nephropathy is defined as urine albumin-to-creatinine ratio $\geq 30 \mathrm{mg}$ albumin/g creatinine, microalbuminuria $\geq 30 \mathrm{mg}$ albumin/g creatinine, and macroalbuminuria $\geq 300 \mathrm{mg}$ albumin/g creatinine. Eye problems includes retinopathy, cataracts, and glaucoma. Because of missing values, the numbers for some variables do not add up to 206. Statistic significant is indicated with bold.

\subsection{Diabetes Control in Young and Older Patients with T2DM}

Table 1 presents the status of diabetes control. For both younger and older patients with diabetes, the mean $\mathrm{HbA1c}$ level was $7.8 \%( \pm 1.4)$. Only one-third of participants $(30.1 \%)$ had good glycemic control $(\mathrm{HbA} 1 \mathrm{c} \leq 7 \%)$, less than half $(36.9 \%)$ had appropriate blood pressure, and less than half $(44.2 \%)$ had appropriate lipid control. Only 8 patients $(4.1 \%)$ presented with normal diabetes control. Younger patients had poorer diabetes control in terms of blood pressure and LDL-C than older patients (Table 1).

\subsection{Daily Habitual Physical Activity in Young and Older Patients with T2DM}

The IPAQ was used to assess patients' daily habitual physical activity, as shown in Table 2. In a week, patients spent 4 days participating in low-intensity activities, with 43.8 min per day on average, and only spent 1.6 days a week with 17.3 min a day participating in moderate- to high-intensity activities. The mean total physical activity for older patients was 1408.9 METs/week and 1373.4 METs/week for younger patients. Physical activity was categorized into three types of dynamic activity. The majority of both younger 
and older patients engaged in low- to moderate-intensity activities and only one-tenth (11.1\%) engaged in high-intensity activities. The average time spent in sedentary behaviors was about $4.8 \mathrm{~h}$ and $5.2 \mathrm{~h}$ a day for younger and older patients, respectively. The younger patients participated in higher intensity activity but less moderate-intensity activity per week than did the older patients. There were no differences in other activity levels between the younger and older groups (Table 2).

Table 2. Status of Daily Physical Activities in Younger ( $\leq 65$ Years) and Older ( $>65$ Years) Patients with T2DM.

\begin{tabular}{|c|c|c|c|c|c|c|c|c|}
\hline & \multicolumn{2}{|c|}{ All Patients } & \multicolumn{2}{|c|}{$\leq 65$ Years } & \multicolumn{2}{|c|}{$>65$ Years } & \multirow[b]{2}{*}{$\mathbf{t}$} & \multirow[b]{2}{*}{$p$} \\
\hline & Mean & SD & Mean & SD & Mean & SD & & \\
\hline \multicolumn{9}{|l|}{$\begin{array}{c}\text { Frequency of performing physical } \\
\text { activity (day/week) }\end{array}$} \\
\hline High intensity physical activities & 0.36 & 1.316 & 0.5 & 1.6 & 0.1 & 0.7 & 2.248 & 0.026 \\
\hline Moderate intensity physical activities & 1.22 & 2.463 & 0.9 & 2.0 & 1.7 & 2.9 & -2.32 & 0.022 \\
\hline Low intensity physical activities & 4.02 & 2.927 & 3.8 & 2.8 & 4.3 & 3.1 & -1.325 & 0.187 \\
\hline \multicolumn{9}{|l|}{$\begin{array}{l}\text { Amount of time spent on physical } \\
\text { activities (minute/day) }\end{array}$} \\
\hline High intensity physical activities & 11.54 & 46.953 & 13.2 & 47.4 & 9.2 & 46.5 & 0.605 & 0.546 \\
\hline Moderate intensity physical activities & 15.78 & 38.615 & 13.8 & 41.0 & 18.6 & 34.9 & -0.894 & 0.373 \\
\hline Low intensity physical activities & 43.77 & 66.508 & 47.1 & 75.4 & 39.1 & 51.6 & 0.855 & 0.393 \\
\hline Sedentary activities ${ }^{1}$ & 300.23 & 131.759 & 290.7 & 133.7 & 314.3 & 128.5 & -1.158 & 0.249 \\
\hline \multicolumn{9}{|l|}{$\begin{array}{l}\text { Amount of time spent on physical } \\
\text { activities (minute/week) }\end{array}$} \\
\hline High intensity physical activities & 40.6 & 202.1 & 51.8 & 226.8 & 24.7 & 160.6 & 0.946 & 0.345 \\
\hline Moderate intensity physical activities & 85.0 & 232.8 & 62.4 & 234.9 & 117.0 & 227.2 & -1.673 & 0.096 \\
\hline Low intensity physical activities & 254.0 & 448.3 & 260.6 & 504.0 & 244.7 & 357.0 & 0.25 & 0.803 \\
\hline \multirow[t]{2}{*}{ Total physical activities (METs) } & 1388.0 & 1954.5 & 1373.4 & 2183.0 & 1408.9 & 1585.5 & 0.946 & 0.345 \\
\hline & $n$ & $\%$ & $n$ & $\%$ & $n$ & $\%$ & $X^{2}$ & $p$ \\
\hline Intensity of physical activities & & & & & & & 0.729 & 0.695 \\
\hline $\begin{array}{l}\text { Performing high intensity of } \\
\text { physical activities }{ }^{3}\end{array}$ & 24 & 11.7 & 13 & 10.7 & 11 & 12.9 & & \\
\hline $\begin{array}{l}\text { Performing moderate intensity of } \\
\text { physical activities }\end{array}$ & 105 & 51.0 & 60 & 49.6 & 45 & 52.9 & & \\
\hline $\begin{array}{l}\text { Performing low intensity of } \\
\text { physical activities } 5\end{array}$ & 77 & 37.4 & 48 & 39.7 & 29 & 34.1 & & \\
\hline
\end{tabular}

Note: ${ }^{1}$. Sedentary behaviors: including sitting for working, reading, watching TV, eating, talking, etc. ${ }^{2}$. Amount of time per day) $\times$ (Frequency of performing physical activities per week). ${ }^{3}$. High-intensity physical activities: Total physical activity $>3000$ METs or high-intensity activity $>1500$ METs a week; ${ }^{4}$. Moderate-intensity activity: Total physical activity $>600$ METs or 20 min of high-intensity activity, $30 \mathrm{~min}$ of moderate- to high-intensity activity for 5 days per week, or $30 \mathrm{~min}$ of walking for 7 days per week; ${ }^{5}$. Low-intensity activity: does not meet the aforementioned criteria. Statistically significant is indicated with bold.

\subsection{Association of Habitual Physical Activity with Diabetes Control in Patients with T2DM}

The Pearson correlation test was performed to examine the association between habitual physical activity and diabetes control (Table 3). The results in all patients showed that performing moderate-intensity activities multiple days a week and minutes a day was significantly correlated with normal levels of blood sugar. Moreover, performing high-intensity activities multiple days a week was correlated with higher levels of blood pressure. However, when the analysis was separated for the younger and older groups, only days a week in performing moderate-intensity activity was significantly correlated with normal blood sugar levels in younger patients. 
Table 3. Association of Performing Physical Activity with Diabetes Control in Patients with T2DM.

\begin{tabular}{|c|c|c|c|c|c|c|c|c|}
\hline & \multicolumn{2}{|c|}{ Glycemic Control } & \multicolumn{2}{|c|}{$\begin{array}{l}\text { Blood Pressure } \\
\text { Control }^{3}\end{array}$} & \multicolumn{2}{|c|}{ LDL-C Control } & \multicolumn{2}{|c|}{$\begin{array}{l}\text { Diabetes } \\
\text { Control }^{4}\end{array}$} \\
\hline & $\mathbf{r}$ & $p$ & $\mathbf{r}$ & $p$ & $\mathbf{r}$ & $p$ & $\mathbf{r}$ & $p$ \\
\hline \multicolumn{9}{|c|}{ All patients } \\
\hline \multicolumn{9}{|l|}{$\begin{array}{c}\text { Frequency of performing physical activity } \\
\text { (day/week) }\end{array}$} \\
\hline High intensity physical activities & -0.040 & 0.564 & 0.155 & 0.027 & 0.102 & 0.155 & 0.036 & 0.612 \\
\hline Moderate intensity physical activities & -0.157 & 0.024 & -0.092 & 0.190 & -0.063 & 0.378 & -0.022 & 0.761 \\
\hline Low intensity physical activities & 0.004 & 0.950 & -0.126 & 0.071 & -0.026 & 0.717 & -0.088 & 0.217 \\
\hline \multicolumn{9}{|l|}{$\begin{array}{l}\text { Amount of time spent on physical activities } \\
\text { (minute/day) }\end{array}$} \\
\hline High intensity physical activities & 0.013 & 0.849 & 0.076 & 0.280 & -0.018 & 0.801 & -0.048 & 0.502 \\
\hline Moderate intensity physical activities & -0.113 & 0.105 & -0.002 & 0.982 & 0.019 & 0.788 & 0.010 & 0.894 \\
\hline Low intensity physical activities & -0.049 & 0.485 & -0.003 & 0.971 & 0.015 & 0.832 & 0.038 & 0.602 \\
\hline Sedentary activities ${ }^{1}$ & 0.042 & 0.584 & -0.12 & 0.115 & -0.044 & 0.578 & -0.094 & 0.232 \\
\hline \multicolumn{9}{|l|}{$\begin{array}{l}\text { Amount of time spent on physical activities } \\
\text { (minute/week })^{2}\end{array}$} \\
\hline High intensity physical activities & 0.054 & 0.439 & 0.123 & 0.077 & 0.027 & 0.704 & 0.018 & 0.805 \\
\hline Moderate intensity physical activities & -0.163 & 0.019 & -0.056 & 0.422 & 0.033 & 0.642 & -0.003 & 0.962 \\
\hline Low intensity physical activities & -0.066 & 0.348 & -0.015 & 0.826 & -0.008 & 0.906 & 0.025 & 0.724 \\
\hline Total physical activities (METs) & -0.099 & 0.158 & 0.036 & 0.610 & 0.029 & 0.687 & 0.027 & 0.711 \\
\hline Intensity of physical activities 5 & -0.113 & 0.106 & -0.009 & 0.903 & 0.020 & 0.783 & -0.036 & 0.613 \\
\hline \multicolumn{9}{|c|}{$\leq 65$ years } \\
\hline \multicolumn{9}{|l|}{$\begin{array}{c}\text { Frequency of performing physical activity } \\
\text { (day/week) }\end{array}$} \\
\hline High intensity physical activities & -0.088 & 0.338 & 0.135 & 0.141 & 0.116 & 0.218 & 0.050 & 0.597 \\
\hline Moderate intensity physical activities & -0.206 & 0.024 & 0.054 & 0.558 & -0.076 & 0.419 & -0.067 & 0.476 \\
\hline Low intensity physical activities & 0.006 & 0.944 & -0.131 & 0.151 & 0.003 & 0.972 & 0.003 & 0.974 \\
\hline \multicolumn{9}{|l|}{$\begin{array}{l}\text { Amount of time spent on physical activities } \\
\text { (minute/day) }\end{array}$} \\
\hline High intensity physical activities & 0.048 & 0.604 & 0.043 & 0.641 & 0.069 & 0.465 & 0.014 & 0.881 \\
\hline Moderate intensity physical activities & -0.107 & 0.244 & 0.106 & 0.249 & 0.008 & 0.934 & 0.025 & 0.790 \\
\hline Low intensity physical activities & -0.007 & 0.937 & -0.136 & 0.140 & 0.008 & 0.934 & 0.071 & 0.454 \\
\hline Sedentary activities 1 & 0.046 & 0.646 & -0.040 & 0.688 & -0.031 & 0.765 & -0.095 & 0.354 \\
\hline \multicolumn{9}{|l|}{$\begin{array}{l}\text { Amount of time spent on physical activities } \\
\qquad(\text { minute/week })^{2}\end{array}$} \\
\hline High intensity physical activities & 0.049 & 0.591 & 0.104 & 0.257 & 0.077 & 0.413 & 0.041 & 0.66 \\
\hline Moderate intensity physical activities & -0.162 & 0.076 & 0.066 & 0.470 & 0.048 & 0.609 & 0.020 & 0.830 \\
\hline Low intensity physical activities & -0.021 & 0.815 & -0.132 & 0.149 & -0.007 & 0.939 & 0.070 & 0.458 \\
\hline Total physical activities (METs) & -0.063 & 0.495 & 0.005 & 0.953 & 0.066 & 0.483 & 0.084 & 0.372 \\
\hline Intensity of physical activities ${ }^{5}$ & -0.080 & 0.381 & -0.036 & 0.693 & 0.048 & 0.614 & 0.023 & 0.803 \\
\hline \multicolumn{9}{|c|}{$>65$ years } \\
\hline \multicolumn{9}{|l|}{$\begin{array}{c}\text { Frequency of performing physical activity } \\
\text { (day/week) }\end{array}$} \\
\hline High intensity physical activities & 0.067 & 0.546 & 0.139 & 0.207 & -0.011 & 0.919 & -0.007 & 0.949 \\
\hline Moderate intensity physical activities & -0.103 & 0.35 & -0.141 & 0.197 & 0.002 & 0.983 & -0.030 & 0.791 \\
\hline Low intensity physical activities & 0.013 & 0.908 & -0.077 & 0.484 & -0.021 & 0.851 & -0.126 & 0.258 \\
\hline \multicolumn{9}{|l|}{$\begin{array}{c}\text { Amount of time spent on physical activities } \\
\text { (minute/day) }\end{array}$} \\
\hline High intensity physical activities & -0.04 & 0.719 & 0.099 & 0.369 & -0.152 & 0.173 & -0.122 & 0.274 \\
\hline Moderate intensity physical activities & -0.117 & 0.285 & -0.118 & 0.281 & 0.064 & 0.565 & -0.005 & 0.967 \\
\hline Low intensity physical activities & -0.145 & 0.187 & 0.190 & 0.082 & 0.000 & 0.997 & 0.037 & 0.738 \\
\hline Sedentary activities ${ }^{1}$ & 0.047 & 0.700 & -0.188 & 0.119 & -0.038 & 0.762 & -0.148 & 0.233 \\
\hline \multicolumn{9}{|l|}{$\begin{array}{c}\text { Amount of time spent on physical activities } \\
\text { (minute/week) }\end{array}$} \\
\hline High intensity physical activities & 0.057 & 0.606 & 0.129 & 0.238 & -0.098 & 0.383 & -0.008 & 0.946 \\
\hline Moderate intensity physical activities & -0.153 & 0.163 & -0.150 & 0.171 & 0.062 & 0.581 & -0.006 & 0.959 \\
\hline Low intensity physical activities & -0.157 & 0.151 & 0.176 & 0.107 & -0.022 & 0.842 & 0.016 & 0.890 \\
\hline Total physical activities (METs) & -0.170 & 0.119 & 0.101 & 0.358 & -0.035 & 0.753 & 0.002 & 0.985 \\
\hline Intensity of physical activities 5 & -0.151 & 0.168 & 0.061 & 0.581 & 0.008 & 0.941 & -0.084 & 0.453 \\
\hline
\end{tabular}

Note: ${ }^{1}$. Sedentary behaviors: including sitting for working, reading, watching TV, eating, talking, etc. ${ }^{2}$. (Amount of time per day) $\times$ (Frequency of performing physical activities per week). ${ }^{3}$. Normal blood-pressure control: systolic blood pressure $<130 \mathrm{mmHg}$ and diastolic blood pressure $<80 \mathrm{mmHg}$ for aged $\leq 65$ years; systolic blood pressure $<140 \mathrm{mmHg}$ and diastolic blood pressure $<90 \mathrm{mmHg}$ for aged $>65$ years. ${ }^{4}$. Overall diabetes control: Normal $=$ all of the $\mathrm{HbA1c}$, blood pressure, and LDL-C are within normal range; abnormal: one of the $\mathrm{HbA1c}$, blood pressure, and LDL-C are out of normal range. ${ }^{5}$. Intensity of physical activities: Low-, Moderate-, and High-intensity activity. Statistically significant is indicated with bold. 
Logistic regression analysis was used to analyze the association between habitual physical activity levels and diabetes control in patients with T2DM based on the results of the above Pearson correlation. As shown in Table 4, the duration of moderate-intensity activity for minutes per day was significantly associated with normal glycemic control, after adjusting for age, sex, and number of years diagnosed with T2DM (Table 4). Every minute per day increased in performing moderate-intensity activity lowered the risk of poor glycemic control by $0.1 \%$.

Table 4. Multiple logistic regression analysis of the association of physical activity with diabetes control in patients with T2DM.

\begin{tabular}{|c|c|c|c|c|c|c|c|c|c|c|}
\hline & \multicolumn{5}{|c|}{ Univariate } & \multicolumn{5}{|c|}{ Multiple } \\
\hline & Wald & $p$ & OR & \multicolumn{2}{|c|}{$95 \%$ CI } & Wald & $p$ & OR & \multicolumn{2}{|c|}{$95 \%$ CI } \\
\hline \multicolumn{11}{|c|}{ On Glycemic Control (HbA1c) } \\
\hline $\begin{array}{c}\text { Frequency of performing moderate physical } \\
\text { activity (day/week) }\end{array}$ & 4.909 & 0.027 & 0.879 & 0.784 & 0.985 & 3.571 & 0.059 & 0.889 & 0.787 & 1.004 \\
\hline Age $(\leq 65 \text { vs. }>65)^{1}$ & 0.555 & 0.456 & 0.796 & 0.436 & 1.452 & 1.557 & 0.212 & 0.648 & 0.328 & 1.281 \\
\hline Sex (female vs. male $)^{2}$ & 0.047 & 0.829 & 0.936 & 0.515 & 1.701 & 0.212 & 0.645 & 0.863 & 0.462 & 1.614 \\
\hline Number of years diagnosed & 4.925 & 0.026 & 1.054 & 1.006 & 1.104 & 6.467 & 0.011 & 1.067 & 1.015 & 1.121 \\
\hline $\begin{array}{l}\text { Performing moderate intensity physical } \\
\text { activities (minutes/week) }\end{array}$ & 4.199 & 0.040 & 0.998 & 0.997 & 1.000 & 3.864 & 0.049 & 0.999 & 0.997 & 1.000 \\
\hline Age $(\leq 65 \text { vs. }>65)^{1}$ & 0.555 & 0.456 & 0.796 & 0.436 & 1.452 & 1.813 & 0.178 & 0.626 & 0.316 & 1.238 \\
\hline Sex (female vs. male $)^{2}$ & 0.047 & 0.829 & 0.936 & 0.515 & 1.701 & 0.289 & 0.591 & 0.842 & 0.449 & 1.578 \\
\hline Number of years diagnosed & 4.925 & 0.026 & 1.054 & 1.006 & 1.104 & 6.943 & 0.008 & 1.070 & 1.017 & 1.124 \\
\hline \multicolumn{11}{|c|}{ On Blood Pressure } \\
\hline $\begin{array}{l}\text { Frequency of performing high physical } \\
\text { activity (day/week) }\end{array}$ & 3.465 & 0.063 & 1.513 & 0.978 & 2.341 & 3.130 & 0.077 & 1.495 & 0.958 & 2.335 \\
\hline Age $(\leq 65 \text { vs. }>65)^{1}$ & 13.345 & 0.000 & 0.335 & 0.186 & 0.602 & 9.556 & 0.002 & 0.364 & 0.192 & 0.691 \\
\hline Sex (female vs. male $)^{2}$ & 0.009 & 0.926 & 0.973 & 0.552 & 1.718 & 0.912 & 0.339 & 0.741 & 0.401 & 1.371 \\
\hline Number of years diagnosed & 4.447 & 0.035 & 0.961 & 0.925 & 0.997 & 0.391 & 0.532 & 0.987 & 0.948 & 1.028 \\
\hline
\end{tabular}

Note. ${ }^{1}$. Age $\leq 65$ is the reference. ${ }^{2}$. Female is the reference. Statistically significant is indicated with bold.

\section{Discussion}

\subsection{Diabetes Control in Young and Older T2DM Patients}

In our study, the mean $\mathrm{HbA} 1 \mathrm{c}$ of all patients was $7.8 \%( \pm 1.4 \%)$, with $69.9 \%$ of patients exhibiting poor glycemic control $(\mathrm{HbA} 1 \mathrm{c}>7 \%)$ and $95.9 \%$ exhibiting poor diabetes control. Only $4.1 \%$ of patients presented favorable diabetes control. In a national survey of 5599 patients with diabetes in Taiwan, $4.1 \%$ achieved the ABC standard in 2006 and $8.6 \%$ achieved the standard in 2011 [16]. Compared with the achievement rate of $14 \%$ demonstrated in the United States from 2007 to 2010 by the United States National Health and Nutrition Examination Survey [3], the number of patients achieving the ABC standard in Taiwan is low. Managing diabetes has become a considerable challenge, especially for individuals 65 years and younger. Literature also showed that younger diabetics had poor glycemic control [17] and increased risks in mortality and complications [2] and need more consideration.

In this study, the younger patients exhibited poorer glycemic control than did the older patients, especially regarding the control of blood pressure and LDL-C. This may be due to the higher proportion of overweight and obese people among the younger patients with diabetes ( $\leq 65$ years) $(71.9 \%$ ) compared with that of the older patients ( $>65$ years) (54.1\%). Obesity increases insulin resistance, which in turn results in poor glycemic control. This phenomenon emphasizes the challenge of controlling obesity, particularly in men aged $\leq 65$ years.

Moreover, number of years with diabetic diagnose was a significant factor for glycemic control in this study. The risk of poor glycemic control kept increased by $6.7 \sim 7 \%$ in every 
year with diabetes diagnosed (Table 4). This result indicated the importance of number of years with diabetes diagnosis. Therefore, preventing metabolic syndrome and delaying the occurrence of diabetes may lower the risk of hyperglycemia, as well as the occurrence of complications, especial for younger adults since they are expected to have longer life than the older adults.

\subsection{Habitual Physical Activity in Young and Older T2DM Patients}

The results of this study showed that the duration of moderate-intensity activity minutes a day was significantly associated with normal glycemic control, after adjusting for age, sex, and number of years diagnosed (Table 4). Every minute a day increased in performing moderate-intensity activity lowered the risk of poor glycemic control by $0.1 \%$. This result was compatible with previous studies showing that physical activity significantly reduced $\mathrm{HbA} 1 \mathrm{c}$ levels by $0.43 \sim 0.67 \%$ [6-8]. Performing moderate-intensity physical activity every day is important for glycemic control, even though daily physical activity differs from exercise [11], with daily physical activity broadly covering exercise, work, walking, housework, gardening, leisure activity, and transportation. The results of this study suggest that any kind of moderate-intensity physical activity counts and not only exercise effects diabetes control. Moderate-intensity activities can be and should be implemented in a person's daily schedule. Since the risk of poor glycemic control was increased by $6.7 \%$ in every number of years diagnosed, but lowered by $0.1 \%$ in every minute a day in performing moderate-intensity activity in this study, performing $67 \mathrm{~min}$ of moderate physical activity per day is required to reverse the risk of poor glycemic control by time. In this study, the older patients with diabetes spent 141.7 min per week performing moderate- to high-intensity activity, whereas the younger patients undertook 114.2 min per week. The amount of time engaged in moderate- to high-intensity physical activity was less than that recommended by the ADA, which is 150 min per week [3]. Although physical activities include exercise, leisure activities, or house activities, patients in this study did not achieve this goal of $150 \mathrm{~min}$ per week. Only one-fourth to one-fifth of patients engaged in moderate- to high-intensity activity at the recommended frequency of a minimum of 3 days per week. These results are similar to those of Wen et al. (2011), in that East Asians, such as Taiwanese people, undertook physical activity less frequently and tended to undertake low-intensity activity, with only one-fifth of East Asians achieving the suggested goals [18].

In addition, the total amount of physical activity engaged in by the older patients with diabetes in the present study was higher than that of the younger patients, which may be due to $88.3 \%$ of the older patients being retired or unemployed. Younger patients generally work and may not have sufficient time to undertake daily physical activities or may not pay too much attention to these physical activities and skip them.

\subsection{Limitations and Implications}

There are some limitations in this study. The participants were recruited using a non-probabilistic convenience sampling process, which may limit the generalizability of the findings. In addition, a short version of the IPAQ was used to quantitatively measure daily physical activity in this study. This measure is subjective, with recall bias possibly causing underestimation or overestimation. However, this seven-item instrument possesses a certain degree of reliability and validity and can achieve a level of physical activity assessment rapidly [13]. This measure is a time- and labor-saving method. In the future, objective instruments, such as an accelerator, may facilitate the investigation of empirical studies on precisely assessing daily physical activity levels. It may also act as a "feedback" to remind people to engage in physical activities. Moreover, physical activity can be divided into three types: home activity, occupational activity, and leisure activity [19]; therefore, there are many opportunities to perform these activities. Future studies that investigate people's difficulties and motivations regarding physical activity thoroughly and identify and overcome factors that affect undertaking physical activity are 
needed. Whether gender and various types of physical activity undertaken by patients with T2DM exhibit an interaction effect on diabetes control must be studied as well. Thus, the goal of controlling diabetes through physical activities can be achieved.

\title{
5. Conclusions and Recommendations
}

In clinical care, patients with diabetes cannot easily meet the criteria of the $\mathrm{ABC}$ standard. Few studies in Taiwan or in other Asian countries have reported the effects of daily physical activity on diabetes control. The present study found that undertaking moderate daily physical activities was significantly associated with better glycemic control. Changes in lifestyle are extremely critical, and non-drug treatment involving physical activity is essential. Younger diabetics is a group of people that needs further consideration. We suggest that patients implement varied physical activities into their daily life and engage in more moderate physical activities for controlling diabetes. Health providers that work with physical exercise professionals may improve the care in performing physical activities for diabetic patients. Future studies to develop a suitable and workable physical activity program or regimen and to investigate people's factors for undertaking physical activities may improve the percentage of those undertaking physical activities.

Author Contributions: Conceptualization, C.-H.C., C.-P.K., C.-N.H., S.-L.H. and M.-C.L.; Formal analysis, W.-C.L.; Supervision, M.-C.L.; Writing—original draft, C.-H.C.; Writing-review \& editing, C.-P.K. and W.-C.L. All authors have read and agreed to the published version of the manuscript.

Funding: This work was supported by the Ministry of Science and Technology, Taiwan, NSC 1002314-B-040-002, and Chung Shan Medical University, CSH 2012-A-002. The above funding agencies had no role in the de-sign of the study, the analysis and interpretation of the data, or the preparation, review, or approval of the manuscript.

Institutional Review Board Statement: This study was approved by the Institutional Review Board of Chun Shan Medical University Hospital (CSMUH CS09025). All participants signed an informed consent form to participate in this study.

Informed Consent Statement: Informed consent was obtained from all subjects involved in the study.

Data Availability Statement: Not applicable because it does not contain any individual persons' data. Please contact the corresponding author for data requests.

Acknowledgments: We thank all the participants in this study and the duty nurses for their time and effort in completing this study. We would like to especially thank research assistants Hsiao-Lin Kuo, Yen-Lin Shen, and Boryi Liao for their data collection and preparation.

Conflicts of Interest: The authors declare no conflict of interest.

\author{
Abbreviations \\ T2DM type II Diabetes mellitus \\ ADA American Diabetes Association \\ HbA1c Hemoglobin A1c \\ IPAQ International Physical Activity Questionnaire. \\ LDL-C low-density lipoprotein cholesterol \\ $\mathrm{VO}_{2}$ max maximal oxygen uptake. \\ $\mathrm{VO}_{2}$ peak peak oxygen uptake. \\ MMSE Mini-Mental State Examination \\ HADS Hospital Anxiety and Depression Scale \\ MET metabolic equivalent
}




\section{References}

1. Jiang, Y.D.; Chang, C.H.; Tai, T.Y.; Chen, J.F.; Chuang, L.M. Incidence and prevalence rates of diabetes mellitus in Taiwan: Analysis of the 2000-2009 Nationwide Health Insurance database. J. Formos Med. Assoc. 2012, 111, 599-604. [CrossRef] [PubMed]

2. Nanayakkara, N.; Curtis, A.J.; Heritier, S.; Gadowski, A.M.; Pavkov, M.E.; Kenealy, T.; Owens, D.R.; Thomas, R.L.; Song, S.; Wong, J.; et al. Impact of age at type 2 diabetes mellitus diagnosis on mortality and vascular complications: Systematic review and meta-analyses. Diabetologia 2021, 64, 275-287. [CrossRef] [PubMed]

3. American Diabetes, A. 14. Diabetes Care in the Hospital: Standards of Medical Care in Diabetes-2018. Diabetes Care 2018, 41, S144-S151. [CrossRef] [PubMed]

4. Asano, R.Y.; Sales, M.M.; Browne, R.A.; Moraes, J.F.; Coelho Junior, H.J.; Moraes, M.R.; Simoes, H.G. Acute effects of physical exercise in type 2 diabetes: A review. World J. Diabetes 2014, 5, 659-665. [CrossRef] [PubMed]

5. Jan, C.F.; Chang, H.C.; Tantoh, D.M.; Chen, P.H.; Liu, W.H.; Huang, J.Y.; Wu, M.C.; Liaw, Y.P. Duration-response association between exercise and HDL in both male and female Taiwanese adults aged 40 years and above. Oncotarget 2018, 9, $2120-2127$. [CrossRef] [PubMed]

6. Irvine, C.; Taylor, N.F. Progressive resistance exercise improves glycaemic control in people with type 2 diabetes mellitus: A systematic review. Aust. J. Physiother. 2009, 55, 237-246. [CrossRef]

7. Umpierre, D.; Ribeiro, P.A.; Kramer, C.K.; Leitao, C.B.; Zucatti, A.T.; Azevedo, M.J.; Gross, J.L.; Ribeiro, J.P.; Schaan, B.D. Physical activity advice only or structured exercise training and association with $\mathrm{HbA1c}$ levels in type 2 diabetes: A systematic review and meta-analysis. JAMA 2011, 305, 1790-1799. [CrossRef] [PubMed]

8. Hansen, D.; Dendale, P.; Jonkers, R.A.; Beelen, M.; Manders, R.J.; Corluy, L.; Mullens, A.; Berger, J.; Meeusen, R.; van Loon, L.J. Continuous low- to moderate-intensity exercise training is as effective as moderate- to high-intensity exercise training at lowering blood $\mathrm{HbA}(1 \mathrm{c})$ in obese type 2 diabetes patients. Diabetologia 2009, 52, 1789-1797. [CrossRef] [PubMed]

9. Van Dijk, J.W.; Tummers, K.; Stehouwer, C.D.; Hartgens, F.; van Loon, L.J. Exercise therapy in type 2 diabetes: Is daily exercise required to optimize glycemic control? Diabetes Care 2012, 35, 948-954. [CrossRef] [PubMed]

10. Hsu, C.H.H.; Tsao, T.H.; Chang, H.W. A preliminary study of recommendations for physical activity for patients with type 2 diabetes. Taiwan J. Public Health 2011, 30, 72-81. [CrossRef]

11. Caspersen, C.J.; Powell, K.E.; Christenson, G.M. Physical activity, exercise, and physical fitness: Definitions and distinctions for health-related research. Public Health Rep. 1985, 100, 126-131. [PubMed]

12. Subramaniam, M.; Zhang, Y.; Lau, J.H.; Vaingankar, J.A.; Abdin, E.; Chong, S.A.; Lee, E.S. Patterns of physical activity and health-related quality of life amongst patients with multimorbidity in a multi-ethnic Asian population. BMC Public Health 2019, 19, 1612. [CrossRef] [PubMed]

13. Mynarski, W.; Psurek, A.; Borek, Z.; Rozpara, M.; Grabara, M.; Strojek, K. Declared and real physical activity in patients with type 2 diabetes mellitus as assessed by the International Physical Activity Questionnaire and Caltrac accelerometer monitor: A potential tool for physical activity assessment in patients with type 2 diabetes mellitus. Diabetes Res. Clin. Pract. 2012, 98, 46-50. [CrossRef] [PubMed]

14. Liou, Y.M.; Jwo, C.J.; Yao, K.G.; Chiang, L.C.; Huang, L.H. Selection of appropriate Chinese terms to represent intensity and types of physical activity terms for use in the Taiwan version of IPAQ. J. Nurs. Res. 2008, 16, 252-263. [CrossRef] [PubMed]

15. Diabetes Association Of The Republic Of China, T. Executive summary of the DAROC clinical practice guidelines for diabetes care-2018. J. Formos Med. Assoc. 2020, 119, 577-586. [CrossRef] [PubMed]

16. Wang, C.Y.; Yu, N.C.; Sheu, W.H.; Tsai, S.T.; Tai, T.Y. Team care of type 2 diabetes mellitus in Taiwan. Diabetes Res. Clin. Pract. 2014, 106 (Suppl. 2), S309-S313. [CrossRef]

17. Nam, G.E.; Han, B.; Joo, C.L.; Kang, S.Y.; Lim, J.; Kim, Y.H.; Park, H.S. Poor Control of Blood Glucose, Lifestyle, and Cardiometabolic Parameters in Younger Adult Patients with Type 2 Diabetes Mellitus. J. Clin. Med. 2019, 8, 1405. [CrossRef] [PubMed]

18. Wen, C.P.; Wai, J.P.; Tsai, M.K.; Yang, Y.C.; Cheng, T.Y.; Lee, M.C.; Chan, H.T.; Tsao, C.K.; Tsai, S.P.; Wu, X. Minimum amount of physical activity for reduced mortality and extended life expectancy: A prospective cohort study. Lancet 2011, 378, 1244-1253. [CrossRef]

19. Golightly, Y.M.; Allen, K.D.; Ambrose, K.R.; Stiller, J.L.; Evenson, K.R.; Voisin, C.; Hootman, J.M.; Callahan, L.F. Physical Activity as a Vital Sign: A Systematic Review. Prev. Chronic Dis. 2017, 14, E123. [CrossRef] [PubMed] 